\title{
Influence of fermentation by-products on the purification of ethanol from water using pervaporation
}

\author{
S. Chovau ${ }^{\text {a }}$, S. Gaykawad ${ }^{\text {b,1 }}$, A.J.J. Straathof ${ }^{\text {b,1 }}$, B. Van der Bruggen ${ }^{\text {a,* }}$ \\ a Department of Chemical Engineering, Laboratory of Applied Physical Chemistry and Environmental Technology, K.U. Leuven, W. de Croylaan 46, B-3001 Leuven, Belgium \\ ${ }^{\mathrm{b}}$ Department of Biotechnology, Delft University of Technology, Julianalaan 67, 2628 BC Delft, The Netherlands
}

\section{A R T I C L E I N F O}

\section{Article history:}

Received 23 July 2010

Received in revised form 21 September 2010

Accepted 23 September 2010

Available online 29 September 2010

\section{Keywords:}

Bio-ethanol

Pervaporation

Fermentation

Carboxylic acids

PDMS

\begin{abstract}
A B S T R A C T
Pervaporation is claimed to be a promising separation technique for the purification of ethanol from fermentation broths during bio-ethanol production. In this study, influence of fermentation by-products on the purification of ethanol from water during hydrophobic pervaporation was investigated.

Sugars and salts were found to increase the membrane performance. Reason for this was a change in vapor/liquid equilibrium. 2,3-Butanediol decreased the ethanol flux and selectivity factor, while glycerol exhibited no effect. This was explained by a strong sorption of butanediol into PDMS and no sorption of glycerol. Due to the presence of carboxylic acids, hydrophobicity degree of the Pervap 4060 membrane decreased, which resulted in an irreversible increase in water flux and decrease in separation performance. These observations suggested the presence of silicalite-based fillers in the membrane. When the $\mathrm{pH}$ was raised to a value above the dissociation constant, no changes in hydrophobicity degree and membrane performance were found.
\end{abstract}

(c) 2010 Elsevier Ltd. All rights reserved.

\section{Introduction}

The combustion of fossil fuels is responsible for more than $70 \%$ of the carbon dioxide production (Balat et al., 2008; Lokhorst and Wildenborg, 2005). The concerns about global warming, and depletion of fossil fuels has increased interest in more sustainable energy sources to mitigate greenhouse gas (GHG) emissions (Lombardi, 2003). Not only $\mathrm{CO}_{2}$ levels but also the emissions of other pollutants, such as $\mathrm{SO}_{2}$ and volatile organic compounds (VOC's) would considerably reduce by replacing fossil fuels with greener equivalents or by wider use of enhanced separation processes (Luis et al., 2009). The transport sector is a significant contributor to GHG emissions and its impact will continue to increase in the future (Abrahamse et al., 2009; Stichnothe and Azapagic, 2009). Reducing emissions in this sector could contribute significantly to reaching the EU targets on climate change.

Ethanol derived from biomass, or bio-ethanol, has been recognized as a potential alternative to petroleum based transportation fossil fuels (Govindaswamy and Vane, 2007). The production of fuel grade ethanol (>99.5 wt.\%) from a raw feedstock is schematically depicted in Fig. 1 and involves four major steps, although some steps are sometimes redundant or can be combined (Balat et al., 2008; Vane, 2005).

\footnotetext{
* Corresponding author. Tel.: +31 152782 330; fax: +31 152782355. E-mail address: Bart.VanderBruggen@cit.kuleuven.be (B. Van der Bruggen).

1 Tel.: +32 163227 26; fax: +32 16322991 .
}

It is well known that ethanol fermentation is inhibited by the ethanol product itself, as a consequence, rather low ethanol concentrations are reached in the final fermentation broths (Nomura et al., 2002). This will be even more significant with the increasing interest in the use of lignocellulosic biomass, which was found to be the most promising feedstock for fermentation processes, due to its availability and low cost (Kim and Dale, 2004). Final ethanol concentrations will be significantly lower ( $<5 \mathrm{wt} . \%)$ than encountered for starch-based feedstocks (Balat et al., 2008).

Conventional distillation (multi-column) is commonly used to purify the ethanol of the fermentation broth but has some disadvantages. These include batch-operation of the fermentor, low glucose-to-ethanol yield and no reuse of salts and microorganisms (Nomura et al., 2002). Moreover, energy requirements increase exponentially when ethanol concentration in the feed solution fall below 5 wt.\% (Madson and Lococo, 2000). Hence, a lot of research was carried out in finding energetically more attractive separation techniques, such as gas/steam stripping (Ezeji et al., 2004), liquidliquid extraction (Bothun et al., 2002), adsorption (Carton et al., 1998) and pervaporation (Bowen et al., 2007; Fadeev et al., 2003; Ikegami et al., 2003; Nomura et al., 2002). These separation technologies for producing fuel grade ethanol from fermentation broths have been extensively reviewed by Vane and compared to the classical distillation process (Vane, 2008). Among proposed technologies, pervaporation may have advantages due to the simplicity of operation, the absence of extra chemicals, low energy requirements and hence low operational cost. Moreover, it was 


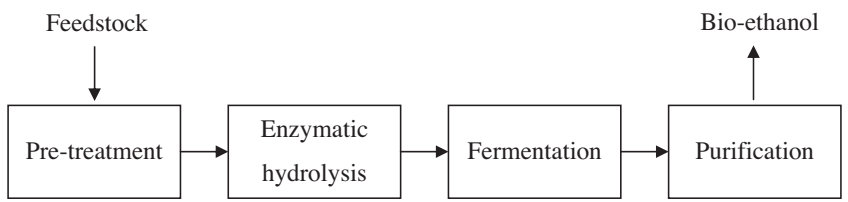

Fig. 1. Schematic flow sheet of bio-ethanol production.

found by several researchers, that a pervaporation unit, coupled to a fermentor will facilitate the fermentor by selectively removing ethanol, hence keeping the ethanol concentration below inhibitory levels for the microorganisms, and thus reducing cost of ethanol (Groot et al., 1993; Kaseno and Kokuga, 1998; O'Brien et al., 2000). O'Brien et al. (2000) performed an economic analysis on replacing the beer column (first distillation column) by a pervaporation unit and found that only modest improvements in the current membrane performance are necessary to become costcompetitive with multi-column distillation.

In addition to ethanol and water, fermentation broths also contain a variety of by-products, which could hinder the purification. Since the first step in a bio-ethanol production process involves the conversion of a feedstock into simple sugars, sugars will always be present during a coupled fermentation-pervaporation process. Glycerol and succinic acid can be present in the fermentation mixture up to 0.8 and $0.4 \mathrm{wt} . \%$, respectively, while concentrations of other carboxylic acids and diols are maximally $0.1 \mathrm{wt} . \%$ (Maiorella, 1983; Vane, 2005). Salts are often added to a fermentation broth to act as a nitrogen or mineral source for microorganisms, and concentrations typically range between 1 and $10 \mathrm{~g} / \mathrm{l}$ (Lin and Tanaka, 2006).

The influence of fermentation by-products on membrane performance during pervaporation has already been investigated by several authors (Aroujaliana et al., 2006; Bowen et al., 2007; Fadeev et al., 2003; García et al., 2009; Ikegami et al., 2003; Nomura et al., 2002). Despite this, sometimes contradictory results were observed between different studies and concrete explanations of observed behavior were missing. However it is clear that the membrane performance can be significantly affected by the presence of fermentation by-products, even in small amounts, which limits the commercial applicability of a pervaporation system.

The aim of this work is to elucidate the effects of different fermentation by-products on the pervaporative isolation of ethanol from aqueous solutions, and to provide solutions to cope with any negative effects on performance. This can assist scientists in optimizing their fermentation broths and will furthermore serve as a useful tool in predicting membrane performance when the composition of a fermentation broth is known.

\section{Methods}

\subsection{Membranes}

Two commercial PDMS-based membranes were investigated in this study, namely Pervap 4060 (Sulzer ChemTech, Switzerland) and Pervatech PDMS (Pervatech BV, The Netherlands). For the sorption experiments a pure PMDS membrane was prepared following Vankelecom et al. (1996).

\subsection{Contact angle measurements}

The standard procedure of contact angle measurement is to put a drop on the top layer of the membrane and to examine the contact angle with a special camera (sessile drop method). In this study, contact angles of a water drop were measured and analyzed at room temperature with a Krüss Drop Shape Analysis System (DSA $10 \mathrm{Mk2}$ ). Contact angles of the membrane were determined before and after experiments to investigate the influence of the feed solution on the hydrophobicity degree. Wet samples were dried in an oven at $40{ }^{\circ} \mathrm{C}$ for $24 \mathrm{~h}$ to remove traces of sorbed liquid. At least five measurements were done on each membrane sample.

\subsection{Pure sorption experiments}

Self-prepared PDMS membrane samples of known weight were immersed into pure liquids at $25^{\circ} \mathrm{C}$ for 2 days. After carefully removing excess of liquid from the surface, the samples were weighed on balance with an accuracy of $10^{-4} \mathrm{~g}$. The amount of sorbed liquid was determined after subtracting the initial mass.

\subsection{Headspace gas chromatography (HSGC)}

HSGC is analysis technique commonly used in studying vaporliquid equilibrium, and allows determining the composition of the vapor phase in a closed system. It involves sampling of the vapor phase, which is in equilibrium with its liquid phase and ejecting in a GC system (Banat et al., 1999). The used apparatus was a PerkinElmer Autosystem XL gas chromatograph (column CromPack, CP Poraplot Q-HT, $25 \mathrm{~m} \times 0.53 \mathrm{~mm}$ ID, FID detector, Waltham, Massachusetts, USA), with an experimental error of $2 \%$. This technique was used to investigate the influence of by-products on the vapor composition of an ethanol in water solution. This will provide a qualitative indication on changes in ethanol and water vapor pressure due to the presence of these components. Since it is unlikely that components in low fractions will significantly affect vapor-liquid equilibrium, the investigated components were added at a concentration of $1 \mathrm{~mol} / \mathrm{l}$. Ethanol concentration was also fixed at $5 \mathrm{wt} . \%$ and the operation temperature was $35^{\circ} \mathrm{C}$.

\subsection{Experimental}

All experiments were carried out with a laboratory pervaporation set-up (Lab Test Cell Unit, Sulzer Chemtech) as described by Dotremont et al. (1994). The feed was heated in a 31 stainless steel container and kept at constant temperature of $30^{\circ} \mathrm{C}$ by a temperature control unit. The feed was circulated over the membrane by a centrifugal pump with a feed flow rate of $250 \mathrm{l} / \mathrm{h}$, resulting in a Reynolds number of approximately 12,000 (turbulent flow) (Bettens et al., 2007). Every 30-90 min, permeate was collected in a glass trap cooled in a Dewar flask containing liquid nitrogen. The vacuum level was maintained below 3 mbar by a two-stage vacuum pump. Flat sheet membranes with an active membrane area of $20 \mathrm{~cm}^{2}$ were used. The total amount of permeate $M_{\text {tot }}$, was determined gravimetrically using a balance with an accuracy of $10^{-4} \mathrm{~g}$ and the total flux $J_{\text {tot }}$ was calculated on the basis of Eq. (1):

$J_{\text {tot }}=\frac{M_{t o t}}{S_{m} \cdot t}$

where $S_{m}$ expresses the active membrane area $\left(\mathrm{m}^{2}\right)$ and $t$ stands for the collection time $(\mathrm{h})$.

Model mixtures of ethanol in water were prepared, in which individual by-products were added at pre-defined concentrations. In all mixtures, feed ethanol concentration was fixed at $5 \mathrm{wt} . \%$. Prior to analysis, membranes were allowed to equilibrate with feed solution for at least $12 \mathrm{~h}$. The effect of residual sugars (glucose and xylose) and salts (ammonium sulfate, $(\mathrm{NH} 4)_{2} \mathrm{SO}_{4}$ ) was also investigated.

Ethanol concentrations were determined by a Shimadzu GC-14A gas chromatograph (column 80/120 Carbopack B/3\% SP - 
1500, FID detector). To prevent salts from precipitation in the GC column, samples containing weak acids were acidified with $\mathrm{HCl}$ prior to GC analysis. The membrane selectivity is commonly expressed by the selectivity factor $\alpha$, as defined by Eq. (2):

$\alpha_{\mathrm{EtOH} / \mathrm{H}_{2} \mathrm{O}}=\frac{\left(w_{\mathrm{EtOH}} / w_{\mathrm{H}_{2} \mathrm{O}}\right)_{p}}{\left(w_{\mathrm{EtOH}} / w_{\mathrm{H}_{2} \mathrm{O}}\right)_{f}}$

where $w_{\mathrm{EtOH}}$ and $w_{\mathrm{H}_{2} \mathrm{O}}$ are the mass fractions of ethanol and water, and $p$ and $f$ denote the permeate side and feed side, respectively. However, in the case of our study where beside ethanol and water also other components are present, it is more convenient to make use of the enrichment factor $\beta$, as defined by Eq. (3). This parameter allows to investigate directly the influence of other components on the enrichment of ethanol in the permeate in comparison to the feed concentration.

$\beta_{\mathrm{EtOH}}=\frac{w_{\mathrm{EtOH}, p}}{w_{\mathrm{EtOH}, f}}$

Finally, partial fluxes $J_{i}$ of water and ethanol are calculated by Eq. (4):

$J_{i}=J_{\text {tot }} \cdot w_{i, p}$

where $w_{i, p}$ represents the mass fraction in the permeate of either ethanol or water. According to the solution-diffusion model, partial flux of component $i$ can be expressed in terms of the actual driving force for permeation, i.e. the vapor pressure difference of that component over the membrane (Baker, 2004):

$J_{i}=\frac{Q_{i}^{m}}{l}\left(p_{i, f}-p_{i_{p}}\right)$

Here $Q_{i}^{m}$ is the intrinsic membrane permeability of component $i, l$ the membrane thickness, $p_{i, f}$ and $p_{i, p}$ represent the partial pressure of component $i$ on feed and permeate side, respectively. When the vacuum level at the permeate side is low enough and components in the feed are not present in trace fractions, the second term in Eq. (5) can be neglected with respect to the first. The equation simplifies to Eq. (6) which states that the partial flux of component $i$ is proportional to the vapor pressure of that component in the feed side.

$J_{i}=\frac{Q_{i}^{m}}{l}\left(p_{i, f}\right)$

Based on the relative error of each measurement method (permeate mass, membrane diameter and GC analysis), the experimental error of the reported performance factors was estimated to be $4 \%$.

\section{Results and discussion}

\subsection{Membrane characterization and performance for a pure ethanol/ water mixture}

The contact angle of a water drop on a dry membrane surface sample was found to be $110^{\circ}$ and $112^{\circ}$ for the Pervap 4060 and Pervatech PDMS membrane, respectively, which is a typical value observed for PDMS-based membranes (Chovau et al., 2010), and indicates a high hydrophobicity degree.

To investigate the influence of different by-products, first a pure ethanol/water mixture was subjected to pervaporation experiments, which will provide a reference for further experiments. The performance parameters of both examined membranes for a 5 wt.\% ethanol-water solution at $30^{\circ} \mathrm{C}$ are summarized in Table 1.

The Pervatech PDMS membrane was found to have a higher flux than the Pervap 4060 membrane but a lower selectivity factor and permeate ethanol concentration, which is in agreement with results observed by Claes et al. (2010).
Table 1

Pervaporation performance of commercial PDMS membranes; feed ethanol concentration: 5 wt.\%; temperature: $30^{\circ} \mathrm{C}$.

\begin{tabular}{llllllll}
\hline Membrane & \multicolumn{2}{l}{ Flux $\left(\mathrm{g} /\left(\mathrm{m}^{2} \mathrm{~h}\right)\right)$} & & $w_{\text {EtOH }, p}($ wt.\% $)$ & $\alpha$ & $\beta$ \\
\cline { 2 - 5 } & Total & EtOH & $\mathrm{H}_{2} \mathrm{O}$ & & & \\
\hline Pervap 4060 & 550 & 169 & 381 & 30.7 & 8.4 & 6.1 \\
Pervatech PDMS & 995 & 214 & 781 & 21.5 & 5.2 & 4.3 \\
\hline
\end{tabular}

\subsection{Influence of by-products on pervaporation performance}

Glycerol and 2,3-butanediol exhibit a very low vapor pressure (Fadeev et al., 2003), which means that the driving force for permeation will be very low. Hence these components can be considered as impermeable and were indeed never detected in the permeate. The same argument holds true for the dissolved glucose, xylose and $\left(\mathrm{NH}_{4}\right)_{2} \mathrm{SO}_{4}$.

\subsubsection{Impermeable components}

The influence of impermeable by-products on the membrane performance of the Pervap 4060 and Pervatech PDMS membrane, together with their concentrations in the tested model mixtures, is presented in Table 2.

In comparison to the pure ethanol/water mixture, the addition of $5 \mathrm{wt}$ \% glucose led to an increase in ethanol permeate concentration of $6 \%$ and $9 \%$ for the Pervap 4060 and Pervatech PDMS membrane, respectively. Smaller increases were found due to addition of $5 \mathrm{wt} . \%$ xylose $(\sim 5 \%)$ and $1 \mathrm{wt} . \%(\mathrm{NH} 4)_{2} \mathrm{SO}_{4}(\sim 3 \%)$. The reason for this increased ethanol permeate concentration was mainly due to an enhanced ethanol flux, which increased for the Pervatech PDMS membrane with $9 \%, 7 \%$ and $6 \%$ due to addition of glucose, xylose and $\left(\mathrm{NH}_{4}\right)_{2} \mathrm{SO}_{4}$, respectively. On the other hand, changes in water flux were found to be smaller than $2 \%$. Furthermore, it was found that ethanol flux and permeate concentration increased with increasing sugar or salt concentration (not shown).

Results are in agreement with Lipnizki et al. (2004), who studied the effect of different salts on the pervaporative separation of propanol/water mixtures trough PDMS membranes. They observed an increased alcohol selectivity, as a result of lower water flux and higher organic flux, which was however only significant above concentrations of $0.5 \mathrm{~mol} / \mathrm{l}$. Moreover, they found that the activity of propanol increased with increasing salt concentration, which is commonly defined as the salting out principle. Banat et al. (1999) demonstrated that vapor-liquid equilibrium and thus vapor pressures could be significantly altered by adding salts to the solution, confirming the salting in/out principle. Using the Headspace Gas Chromatography (HSGC) technique, they observed a higher ethanol fraction in the vapor phase when salts were added to an ethanol water solution. The higher ethanol vapor fraction can only be attributed to a decrease in the vapor pressure of water, an increase in vapor pressure of ethanol, or both. It must be noted that experiments were only done at high salt loadings (from $1 \mathrm{~mol} / \mathrm{l}$ up to saturated solutions). From literature it was found that in a $38 \mathrm{wt} . \%$ ethanol/water solution at $20^{\circ} \mathrm{C}$, the vapor pressure of ethanol increased with $5 \%$ and water decreased with $18 \%$, in the presence of $0.072 \mathrm{~mol} / \mathrm{l}$ sucrose (Aroujaliana et al., 2006). This was explained by preferential interaction of hydroxyl groups in the sugar with water through hydrogen bonding, since ethanol has only one pole for hydrogen bonding, and moreover a more hydrophobic tail. This preferential bonding of sugar to water decreased the vapor pressure of water and increased the ethanol vapor pressure due to lower bonding capacity of water molecules with ethanol. Since glucose and xylose also exhibit hydroxyl groups for hydrogen bonding, it is likely that these sugars have a similar effect as sucrose on vapor-liquid equilibrium. 
Table 2

Influence of fermentation by-products on performance of the examined membranes; feed ethanol concentration: 5 wt.\%; temperature: $30{ }^{\circ} \mathrm{C}$.

\begin{tabular}{|c|c|c|c|c|c|c|c|}
\hline Membrane & & $\begin{array}{l}\text { Additive } \\
\text { Concentration (wt.\%) }\end{array}$ & $\begin{array}{l}\text { Glucose } \\
5\end{array}$ & $\begin{array}{l}\text { Xylose } \\
5\end{array}$ & $\begin{array}{l}\text { Salts } \\
1\end{array}$ & $\begin{array}{l}\text { Glycerol } \\
1\end{array}$ & $\begin{array}{l}\text { 2,3-Butanediol } \\
0.1\end{array}$ \\
\hline \multirow[t]{5}{*}{ Pervap 4060} & Flux $\left(g /\left(m^{2} h\right)\right)$ & Total & 555 & 550 & 554 & 545 & 517 \\
\hline & & EtOH & 181 & 175 & 174 & 166 & 140 \\
\hline & & Water & 374 & 375 & 380 & 379 & 377 \\
\hline & $w_{\mathrm{EtOH}, p}(\mathrm{wt} . \%)$ & & 32.6 & 31.9 & 31.5 & 30.4 & 27.1 \\
\hline & Enrichment $\beta$ & & 6.5 & 6.4 & 6.3 & 6.1 & 5.4 \\
\hline \multirow[t]{5}{*}{ Pervatech PDMS } & Flux $\left(g /\left(m^{2} h\right)\right)$ & Total & 1011 & 1007 & 1005 & 990 & 966 \\
\hline & & EtOH & 233 & 229 & 226 & 213 & 182 \\
\hline & & Water & 778 & 778 & 779 & 777 & 785 \\
\hline & $w_{\mathrm{EtOH}, p}(\mathrm{wt} . \%)$ & & 23.4 & 23.1 & 22.4 & 21.5 & 18.8 \\
\hline & Enrichment $\beta$ & & 4.6 & 4.6 & 4.5 & 4.3 & 3.8 \\
\hline
\end{tabular}

Headspace-GC analysis of the vapor composition of ethanol/ water solutions in which glucose, xylose or $\left(\mathrm{NH}_{4}\right)_{2} \mathrm{SO}_{4}$ were added is presented in Fig. 2.

From Fig. 2, it can be concluded that both sugars and salts significantly increase the vapor pressure of ethanol and decrease the vapor pressure of water, when present in sufficiently high concentrations. In our study, molar concentrations varied between 0.08 and $0.35 \mathrm{~mol} / \mathrm{l}$, and the positive changes in performance factors ranged around the experimental error.

Addition of 1 wt.\% glycerol did not significantly affect fluxes or permeate ethanol concentration for both membranes. This is in contrast to Ikegami et al. (2003), who observed for an ethanol/glycerol/water solution $(5 \% / 0.8 \% / 94.2 \%(\mathrm{w} / \mathrm{w}))$ at $30{ }^{\circ} \mathrm{C}$ a significant decrease in total flux through a silicone rubber coated silicalite membranes in comparison to a pure ethanol/water mixture, thereby not altering the permeate composition. The decreased total flux was explained by the assumption that the addition of glycerol leads to a decrease in vapor pressure of both ethanol and water. García et al. (2009) observed a similar trend through a POMS membrane for a $1 \mathrm{wt} . \%$ glycerol/9.5 wt.\% ethanol solution at 34 and $53{ }^{\circ} \mathrm{C}$. The authors calculated the activity coefficients of the ternary glycerol/ethanol/water mixture, but found no significant differences in comparison to the binary ethanol/water mixture.

Presence of $0.1 \mathrm{wt} . \%$ of 2,3-butanediol decreased ethanol flux by 17\% and 22\% for Pervap 4060 and Pervatech PDMS membrane, respectively, whereas water flux was not significantly affected. This resulted in a permeate concentration which was $\sim 12 \%$ lower than in the absence of 2,3-butanediol. Fadeev et al. (2003) found that butanediols strongly adsorb on a poly[1-(trimethylsilyl)-1propyne] (PTMSP) membrane. To verify whether this was also the case for a PDMS-based membrane, the sorption of pure components on PDMS samples was measured, which is presented in Fig. 3.

From this figure, it can be seen that total sorption of 2,3-butanediol into PDMS is significantly higher (37\%) in comparison to etha-

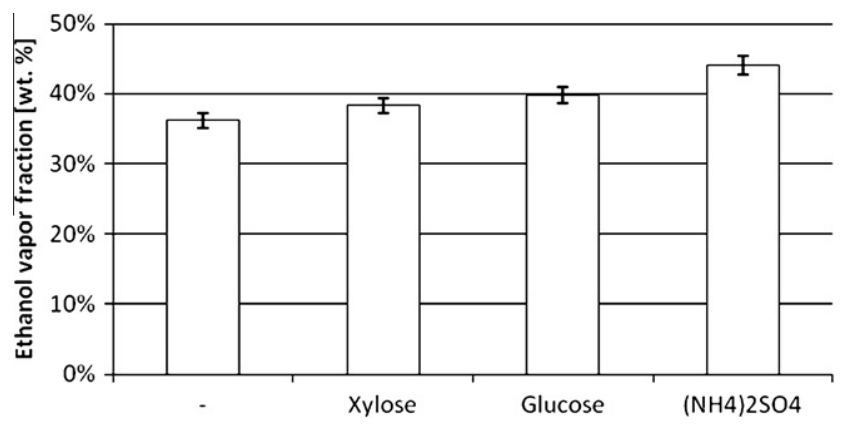

Fig. 2. Influence of addition of components ( $1 \mathrm{~mol} / \mathrm{l})$ on vapor composition; ethanol concentration in liquid phase: $5 \mathrm{wt} . \%$; operation temperature: $35^{\circ} \mathrm{C}$.

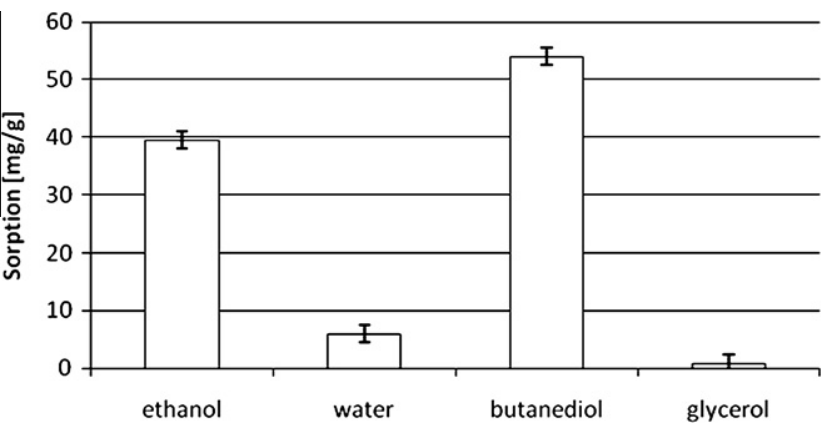

Fig. 3. Sorption of pure components in a pure PDMS membrane.

nol. It is thus likely that butanediol molecules will compete with ethanol molecules for adsorption sites on the examined membranes, which explains the decrease in ethanol selectivity. Furthermore, glycerol showed no sorption at all into the PDMS membrane. Hence no interaction of glycerol with the membrane can occur and membrane performance is not altered. Sorption experiments are thus a key factor in determining the affinity of a component for a membrane material and the probable interaction with it.

Though addition of these components to an ethanol/water mixture influenced the membrane performance to some extent, membrane properties were completely restored when membranes were afterwards subjected to pure ethanol/water experiments. Hence, these components form no risk of deteriorating the membrane and will not alter the membrane performance of a real fermentation broth mixture to a large extent, since typical encountered concentrations will be lower than tested here.

\subsubsection{Influence of carboxylic acids}

The influence of the presence of carboxylic acids at $0.1 \mathrm{wt} . \%$ in the feed solution on the membrane performance for the Pervap 4060 and Pervatech PDMS membrane is presented in Table 3.

From Table 3, it is clear that the water flux through the Pervap 4060 was significantly increased due to addition of weak acids. Moreover, with increasing molar concentration of acid in the solution, the water flux increased from $19 \%$ for succinic acid up to $48 \%$ for formic acid. This enhanced water flux, in combination with a more or less similar ethanol flux, resulted in a $10-20 \%$ lower ethanol concentration in the permeate, in comparison to the pure ethanol/water mixture. When membrane samples were afterwards subjected to pure ethanol/water solution, membrane properties were not restored. For the Pervatech PDMS membrane, only a slight decrease (1-6\%) in permeate ethanol concentration was observed and membrane properties were not altered afterwards. This suggests that there must be a clear difference in interaction of components with the membrane between the two commercial membranes. 
Table 3

Influence of addition of $0.1 \mathrm{wt} . \%$ of weak acids on performance of examined membranes; feed ethanol concentration: 5 wt.\%; temperature: $30{ }^{\circ} \mathrm{C}$.

\begin{tabular}{|c|c|c|c|c|c|c|c|c|}
\hline \multirow{2}{*}{$\begin{array}{l}\text { Membrane } \\
\text { Pervap } 4060\end{array}$} & \multicolumn{2}{|c|}{$\begin{array}{l}\text { Added acid } \\
\text { Concentration }(\mathrm{mmol} / \mathrm{l})\end{array}$} & \multirow{2}{*}{$\begin{array}{l}\text { Pure } \\
- \\
550\end{array}$} & \multirow{2}{*}{$\begin{array}{l}\text { Acetic } \\
16.4 \\
742.5\end{array}$} & \multirow{2}{*}{$\begin{array}{l}\text { Succinic } \\
8.4 \\
627\end{array}$} & \multirow{2}{*}{$\begin{array}{l}\text { Formic } \\
21.4 \\
748\end{array}$} & \multirow{2}{*}{$\begin{array}{l}\text { Lactic } \\
10.9 \\
687.5\end{array}$} & \multirow{2}{*}{$\begin{array}{l}\text { Butyric } \\
11.2 \\
654.5\end{array}$} \\
\hline & Flux $\left(\mathrm{g} /\left(\mathrm{m}^{2} \mathrm{~h}\right)\right)$ & Total & & & & & & \\
\hline & & EtOH & 168.6 & 187.1 & 172.3 & 184 & 185.1 & 178 \\
\hline & & Water & 381.4 & 555.4 & 454.7 & 564 & 502.4 & 476.5 \\
\hline & $w_{\mathrm{EtOH}, p}(\mathrm{wt} . \%)$ & & 30.7 & 25.2 & 27.5 & 24.6 & 26.9 & 27.2 \\
\hline & Enrichment $\beta$ & & 6.13 & 5.04 & 5.5 & 4.92 & 5.38 & 5.44 \\
\hline \multirow[t]{5}{*}{ Pervatech PDMS } & Flux $\left(\mathrm{g} /\left(\mathrm{m}^{2} \mathrm{~h}\right)\right)$ & Total & 995 & 986 & 983 & 995 & 973 & 980 \\
\hline & & EtOH & 214 & 209 & 199 & 212 & 197 & 198 \\
\hline & & Water & 781 & 777 & 784 & 783 & 776 & 782 \\
\hline & $w_{\mathrm{EtOH}, p}(\mathrm{wt} . \%)$ & & 21.5 & 21.2 & 20.2 & 21.3 & 20.2 & 20.2 \\
\hline & Enrichment $\beta$ & & 4.3 & 4.24 & 4.05 & 4.26 & 4.05 & 4.04 \\
\hline
\end{tabular}

Ikegami et al. (2003) investigated the membrane performance through silicalite membranes and found that the permeate ethanol concentration was significantly decreased due to the addition of $0.3 \mathrm{wt} . \%$ succinic acid to a $5 \mathrm{wt}$.\% ethanol/water solution. Moreover, the infrared spectra of silicalite powder immersed in succinic acid, showed stretching vibration peaks of carbonyl and carboxyl groups and deformed hydroxyl groups. The authors suggested that the silicate membrane became hydrophilic due to adsorption of succinic acid on the silicalite surface. However, no changes in infrared spectra were observed when a pure silicone rubber material was immersed in the same succinic acid solution. Bowen et al. (2007) investigated the stability of zeolite-filled (silicalite-1 and CBV28014 ZSM-5) PDMS membranes during pervaporative ethanol recovery from aqueous solutions. They observed no significant change in membrane performance due to addition of $1 \mathrm{wt} . \%$ acetic acid to a $5 \mathrm{wt} . \%$ ethanol in water solution for an unfilled PDMS membrane, but an irreversible decrease in both ethanol flux and selectivity factor for zeolite-filled. The authors also attributed this behavior to the interaction of acetic acid with silanol ( $\mathrm{Si}-\mathrm{OH}$ ) groups terminating the external surface of the zeolite particle, forming $\mathrm{Si}-\mathrm{O}-\mathrm{COCH}_{3}$ bonds.

An explanation for the strongly enhanced water flux, observed in our study, was found by measuring the hydrophobicity degree of the membrane surface after the experiments with acid solutions. Starting from a dry membrane with contact angle of $110^{\circ}$, contact angles of the membrane samples decreased due to the presence of carboxylic acids to values ranging from $87^{\circ}$ to $94^{\circ}$. Moreover a higher decrease was observed for an acid with lower molecular weight. This increase in hydrophilicity degree of the membrane is thus responsible for the increased water permeation, whereas the increased ethanol flux can be attributed to coupling effects.

In literature it was found that the PDMS backbone can be hydrolyzed by water at low $\mathrm{pH}$ (Bowen et al., 2007), and the resulting silanol group on the polymer would be, similar to zeolite surfaces, available for interaction with weak acids. However, hydrolysis of the PDMS backbone would already result in lower hydrophobicity, which was not observed for the Pervatech PDMS membrane. When both membranes were subjected to an ethanol/water mixture, in which $\mathrm{HCl}$ was added to reach a similar $\mathrm{pH}$ as in the weak acid solutions, no effect was observed in membrane performance or hydrophobicity degree. From this, the assumption can be made that Si-based zeolites are present in the Pervap 4060 membrane, and observations would be in agreement with Bowen et al. (2007), as described earlier. This would also confirm the observed trend that a stronger molar concentration of weak acid decreased the hydrophobicity degree most due to more molecules available for interaction with the silanol groups.

It was also found that the $\mathrm{pH}$ of the acid solutions played an important role during pervaporation experiments of the Pervap 4060 membrane. When the $\mathrm{pH}$ of the solution was increased by addition of $\mathrm{NaOH}$, to a value above the dissociation constant of the acid, no significant change in membrane performance or hydrophobicity degree was observed. Bowen et al. (2007) observed similar behavior for a ZSM-5 filled PDMS membrane. While membrane performance was drastically decreased when no pH correction was made, no change in water and ethanol fluxes were found when the $\mathrm{pH}$ was increased above the weak acid dissociation constant. They explained this by the fact that dissociated ions, which are mainly present above the dissociation constant of the weak acid, adsorb less strong on the zeolite particles. This was also confirmed by Efe et al. (2010) for the adsorption of succinic acid on the same type of ZSM-5 zeolite. From literature, it was found that microorganisms produce ethanol more efficiently in environments closer to neutral pH (Bowen et al., 2007). In the light of developing high performance membranes, based on mixed matrix systems with inorganic fillers, it is advisable to increase the $\mathrm{pH}$ during fermentation processes in order to minimize the impact of organic acids on membrane performance.

\section{Conclusions}

During purification of ethanol from water by pervaporation, presence of sugars and salts non-significantly increased the membrane performance, due to increased relative volatility between ethanol and water. 2,3-Butanediol sorbed 37\% stronger than ethanol in PDMS and hence decreased ethanol permeate concentration by $12 \%$.

Weak acids rendered the Pervap 4060 membrane more hydrophilic, resulting in an increase in water flux up to $48 \%$ and reduction in ethanol permeate concentration up to $20 \%$. This membrane fouling was explained by interaction of acids with silanol groups of the Si-based fillers, but could be avoided by increasing the $\mathrm{pH}$ towards more neutral environments.

\section{Acknowledgements}

The work leading to these results has received funding from the European Community's Seventh Framework Programme (FP7/ 2007-2013) under Grant Agreement No. NMP3-SL-2009-228631, project DoubleNanoMem.

\section{References}

Abrahamse, W., Steg, L., Gifford, R., Vlek, C., 2009. Factors influencing car use for commuting and the intention to reduce it: a question of self-interest or morality? Transp. Res. F 12 (4), 317-324.

Aroujaliana, A., Belkacemib, K., Davids, S.J., Turcotted, G., Pouliot, Y. 2006. Effect of residual sugars in fermentation broth on pervaporation flux and selectivity for ethanol. Desalination 193, 103-108.

Baker, R.W., 2004. Membrane Technology and Applications, second ed. John Wiley and Sons, Ltd., pp. 39-44, 139-155.

Balat, M., Balat, H., Oz, C., 2008. Progress in bioethanol processing. Prog. Energy Combust. Sci. 34, 551-573. 
Banat, F.A., Al-Rub, F. Abu, Simandl, J., 1999. Experimental study of the salt effect in vapor/liquid equilibria using headspace gas chromatography. Chem. Eng. Technol. 22 (9), 761-765.

Bettens, B., Degrève, J., Van der Bruggen, B., Vandecasteele, C., 2007. Transport of binary mixtures in pervaporation through a microporous silica membrane: shortcomings of Fickian models. Sep. Sci. Technol. 42 (1), 1-23.

Bothun, G.D., Knutson, B.L., Strobel, H.J., Nokes, S.E., Brignole, E.A., Diaz, S., 2002. Compressed solvents for the extraction of fermentation products within a hollow fiber membrane contactor. J. Supercrit. Fluids 25, 119-134.

Bowen, T.C., Meier, R.G., Vane, L.M., 2007. Stability of MFI zeolite-filled PDMS membranes during pervaporative ethanol recovery from aqueous mixtures containing acetic acid. J. Membr. Sci. 298, 117-125.

Carton, A., Benito, G.G., Rey, J.A., de la Fuente, M., 1998. Selection of adsorbents to be used in an ethanol fermentation process. Adsorption isotherms and kinetics. Bioresour. Technol. 66, 75-78.

Chovau, S., Dobrak, A., Figoli, A., Simone, S., Galiano, F., Drioli, E., Sikdar, S.K., Van der Bruggen, B., 2010. Pervaporation performance of unfilled and filled PDMS membranes and novel SBS membranes for the removal of toluene from diluted aqueous solutions. Chem. Eng. J. 159 (1-3), 37-46.

Claes, S., Vandezande, P., Mullens, S., Leysen, R., De Sitter, K., Andersson, A., Maurer, F.H.J., Van den Rul, H., Peeters, R., Van Bael, M.K., 2010. High flux composite PTMSP-silica nanohybrid membranes for the pervaporation of ethanol/water mixtures. J. Membr. Sci. 351, 160-167.

Dotremont, C., Van den Ende, S., Vandommele, H., Vandecasteele, C., 1994. Concentration polarization and other boundary layer effects in the pervaporation of chlorinated hydrocarbons. Desalination 95, 91-113.

Efe, Ç., van der Wielen, L.A.M., Straathof, A.J.J., 2010. High silica zeolites as an alternative to weak base adsorbents in succinic acid, recovery. Ind. Eng. Chem. Res. 49 (4), 1837-1843.

Ezeji, T.C., Qureshi, N., Blaschek, H.P., 2004. Acetone butanol ethanol (ABE) production from concentrated substrate: reduction in substrate inhibition by fed-batch technique and product inhibition by gas stripping. Appl. Microbiol. Biotechnol. 63, 653-658.

Fadeev, A.G.Kelley, S.S., McMillan, J.D., Selinskaya, Ya.A., Khotimsky, V.S., Volkov, V.V., 2003. Effect of yeast fermentation by-products on poly[1-(trimethylsilyl)-1propyne] pervaporative performance. J. Membr. Sci. 214, 229-238.

García, M., Sanz, M.T., Beltran, S., 2009. Separation by pervaporation of ethanol from aqueous solutions and effect of other components present in fermentation broths. J. Chem. Technol. Biotechnol. 84, 1873-1882.

Govindaswamy, S., Vane, L.M., 2007. Kinetics of growth and ethanol production on different carbon substrates using genetically engineered xylose-fermenting yeast. Bioresour. Technol. 98, 677-685.
Groot, W.J., Kraayenbrink, M.R., van der Lans, R.G.J.M., Luyben, K.C.H.A.M., 1993. Ethanol production in an integrated fermentation/membrane system. Process simulations and economics. Bioproc. Eng. 8, 189.

Ikegami, T., Kitamoto, D., Negishi, H., Haraya, K., Matsuda, H., Nitanai, Y., Koura, N. Sano, T., Yanagishita, H., 2003. Drastic improvement of bioethanol recovery using a pervaporation separation technique employing a silicone rubber-coated silicalite membrane. J. Chem. Technol. Biotechnol. 78, 1006-1010.

Kaseno, Miyazawa I., Kokuga, T., 1998. Effect of product removal by a pervaporation on ethanol fermentation. J. Ferment. Bioeng. 86 (5), 488-493.

Kim, S., Dale, B.E., 2004. Global potential bioethanol production from wasted crops and crop residues. Biomass Bioenergy 26, 361-375.

Lin, Y., Tanaka, S., 2006. Ethanol fermentation from biomass resources: current state and prospects. Appl. Microbiol. Biotechnol. 69 (6), 627-642.

Lipnizki, F., Hausmanns, S., Field, R.W., 2004. Influence of impermeable components on the permeation of aqueous 1-propanol mixtures in hydrophobic pervaporation. J. Membr. Sci. 228, 129-138.

Lokhorst, A., Wildenborg, I., 2005. Introduction on $\mathrm{CO}_{2}$ Geological storage Classification of storage options. Oil Gas Sci. Technol. Rev. IFP 60 (3), 513-515.

Lombardi, L. 2003. Life cycle assessment comparison of technical solutions for $\mathrm{CO}_{2}$ emissions reduction in power generation. Energy Convers. Manage. 44, 93-108.

Luis, P., Garea, A., Irabien, A., 2009. Zero solvent emission process for sulfur dioxide recovery using a membrane contactor and ionic liquids. J. Membr. Sci. 330 (1-2), 80-89.

Madson, P.W., Lococo, D.B., 2000. Recovery of volatile products from dilute highfouling process streams. Appl. Biochem. Biotechnol. 84-86, 1049-1061.

Maiorella, B.L., 1983. Ethanol industrial chemicals. Biochem. Fuels, 861-914.

Nomura, M., Bin, T., Nakao, S.-I., 2002. Selective ethanol extraction from fermentation broth using a silicalite membrane. Sep. Purif. Technol. 27, 59-66

O'Brien, D.J., Roth, L.H., McAloon, A.J., 2000. Ethanol production by continuous fermentation-pervaporation: a preliminary economic analysis. J. Membr. Sci. 166, 105-111.

Stichnothe, H.Azapagic, A., 2009. Bioethanol from waste: life cycle estimation of the greenhouse gas saving potential. Resour. Conserv. Recycl. 53, 624-630.

Vane, L.M., 2005. A review of pervaporation for product recovery from biomass fermentation processes. J. Chem. Technol. Biotechnol. 80, 603-629.

Vane, L.M., 2008. Separation technologies for the recovery and dehydration of alcohols from fermentation broths. Biofuels Bioprod. Bioref. 2, 553-588.

Vankelecom, I.F.J., Jacobs, P.A., Uytterhoeven, J.B., 1996. Method for preparing membranes, said membranes, separation methods using said membranes and the use of said membranes as catalytic membranes. European Patent, EP 96201340.5-2113. 